\title{
KESESUAIAN BAHAN PEMBUATAN KAPAL PURSE SEINE BERDASARKAN ATURAN BIRO KLASIFIKASI INDONESIA DI DESA PAGARUYUNG KECAMATAN KUSAN HILIR
}

\author{
Suitability of Material Making of Purse Seiner Based on Indonesian Classification Bureau \\ Rules in Pagaruyung Village, Kusan Hilir District \\ Oleh: \\ Normalina Chatimah, Iriansyah, AuliaAzhar Wahab \\ Program Studi Pemanfaatan Sumberdaya Perikanan, Universitas Lambung Mangkurat, Indonesia \\ * Korespondensi : normalina.net@gmail.com
}

\begin{abstract}
The construction of wooden ships in the Pagaruyung Village shipyard is done traditionally with written knowledge from generation to generation so that the design is not known to be in accordance with the rules of the Indonesian Classification Bureau (BKI). The purpose of this research is to find out the material for purse seine vessels using BKI rules. This research is a case study using numerical analysis obtained by measurements and observations then compared with $B K I$ rules. The results showed that the wood material used was ulin wood (Eusideroxylon zwageri) which was used on the keel part, bow height and stern level, ivory, galar beam, deck beam, deck beam, leather board and engine foundation, alaban or laban wood (Vitex pubesceus) is used on deck boards, fish hatches, buildings and leather boards. Ship construction is not in accordance with the regulations set by BKI, purse seine ship construction is a mixed or combination construction.
\end{abstract}

Keywords: construction stages, material suitability, purse seine, BKI

\begin{abstract}
ABSTRAK
Pembangunan kapal kayu di galangan Desa Pagaruyung dilakukan secara tradisional dengan pengetahuan yang tertulis secara turun temurun sehingga tidak diketahui rancangan tersebut sesuai atau tidak dengan aturan Biro Klasifikasi Indonesia (BKI). Tujuan penelitian mengetahui material kapal purse seine dengan menggunakan aturan BKI. Penelitian ini merupakan studi kasus dengan menggunakan analisis numerik yang diperoleh dengan pengukuran dan pengamatan kemudian dibandingkan dengan aturan BKI. Hasil penelitian menunjukan, material kayu yang digunakan adalah kayu ulin (Eusideroxylon zwageri) yang digunakakan pada bagian lunas, linggi haluan dan linggi buritan, gading-gading, galar balok, balok geladak, papan kulit dan pondasi mesin, kayu alaban atau laban (Vitex pubesceus) digunakan pada bagian papan geladak, palka ikan, bangunan dan papan kulit. Konstruksi kapal tidak sesuai dengan aturan yang ditetapkan BKI, Konstruksi kapal purse seine adalah konstruksi campuran atau kombinasi.
\end{abstract}

Kata kunci: kesesuaian material, tahapan konstruksi, purse seine, BKI

\section{PENDAHULUAN}

Kapal kayu nelayan di Indonesia umumnya dibuat secara tradisional, pembangunan dilakukan tanpa perencanaan dan syarat umum dan tidak adanya gambar desain kapal berupa general arrangement, lines plan, midship section ataupun construction profile untuk digunakan sebagai syarat teknis yang harus dipenuhi. Hal tersebut bisa terjadi karena selama proses pembangunan kapal hanya berdasarkan dari pengetahuan tertulis secara turun temurun (Febriyansyah et al. 2009). 
Berdasarkan Rusmilyansari et al. (2014), menyatakan bahwa komponen dalam menentukan keberhasilan operasi penangkapan ikan selain dari nelayan dan alat tangkap adalah kapal pengoperasian. Pembangunan kapal penangkapan di Kalimantan Selatan umumnya bersifat tradisional. Iskandar dan Novita (2000), menyatakan tradisional dimaksudkan kepada metode yang digunakan pengrajin dalam membuat kapal berdasarkan teknik yang diwariskan para pendahulu.

BKI (Biro Klasifikasi Indonesia) adalah badan hukum dibidang jasa yang berusaha dalam pengklasifikasian kapal yang sedang dibangun, sudah dibangun atau sedang beroperasi dalam hal yang berkaitan dengan kontruksi badan kapal, dII. BKI merupakan badan klasifikasi nasional yang diberikan kewenangan oleh Pemerintah Indonesia untuk mengklasifikasikan kapal niaga berbendera Indonesia.

Bahan pembuatan kapal digalangan khususnya untuk daerah pagatan, dikenal sebagai sentral pembuatan kapal di daerah Kalimantan Selatan, material yang digunakan menggunakan bahan yang sesuai atau tidak sesuai, khususnya pada kontruksi kapal purse seine sebagai perbandingan dengan menggunakan aturan BKI (Biro Klasifikasi Indonesia). Hal tersebut bisa di lihat pada BKI karena sudah memuat tatanan atau peraturan bagaimana kapal yang layak untuk digunakan untuk usaha perikanan tangkap. Penerapan standar BKI dalam pembangunan kapal penangkap ikan sangat penting untuk memastikan kekuatan konstruksi kapal dan keselamatan kerja anak buah kapal saat kegiatan operasi penangkapan ikan.

Penelitian ini bertujuan untuk mengetahui perbandingan material kapal purse seine nelayan tradisional di Desa Pagaruyung menurut Biro Klasifikasi Indonesia (BKI); mengetahui konstruksi kapal purse seine serta mengetahaui pembuatan kapal ikan di galangan kapal.

\section{METODE}

Penelitian dilaksanakan selama 4 bulan di Desa Pagaruyung, Kecamatan Kusan Hilir. Alat yang digunakan dalam penelitian adalah, water pass, alat ukur (meteran rol dan penggaris kayu), tali tambang serta pendulum (bandul), alat tulis, leptop dan kamera.

Metode pengambilan data menggunakan studi kasus dengan teknik purposive sampling, sampel yang diambil berupa kapal purse seine berdasarkan syarat yang telah di tetapkan oleh BKI (Biro Klasifikasi Indonesia) mengenai kesesuaian bahan pembuatan kapal kemudian tahapan tahapan pembuatan dari perakitan sampai dengan kapal tersebut selesi. Menurut Suharsimi (2002), pengambilan data dengan Purposive Sample dilakukan dengan mengambil subyek bukan berdasarkan strata, random atau daerah, namun didasarkan atas adanya tujuan tertentu. Teknik ini dilakukan karena beberapa pertimbangan, misalnya alasan keterbatasan waktu, tenaga atau dana sehingga tidak dapat mengambil sampel yang besar serta jauh. Data yang digunakan dalam penelitian dilakukan dengan 2 cara deskriptif dan numerik yang termasuk dalam data primer dan sekunder.

Analisi data pada kapal purse seine dilkukan dengan cara menghitung GT pada kapal, jika panjang kapal kurang dari $24 \mathrm{~m}$, maka menggunakan rumus menurut Dirjen PERLA No.PY.67/1/16-02.

$$
\mathrm{GT}=0,25 \times \mathrm{V}
$$

Dimana :

$V=$ Jumlah isi dari ruangan di bawah geladak atas dengan ruangan diatas geladak yang tertutup sempurna yang berukuran tidak $<1 \mathrm{~m}^{3}$.

$0,25=$ Nilai konversi dari satuan meter kubik ke ton register

Analisis konstruksi pada kapal dilakukan dengan cara identifikasi material yang digunakan pada pembangunan kapal purse seine. Data ini diperoleh dari wawancara dengan pembuat kapal dan pemilik kapal yang meliputi jenis material dan juga dilakukan pengukuran mengenai konstruksi 
kapal purse seine yang diteliti. Analisis data konstruksi kapal menggunakan persamaan (BKI, 1996):

$$
Z=(B / 3+D) L
$$

Dimana : $Z$ = Angka petunjuk $\left(\mathrm{m}^{2}\right)$

$$
\begin{aligned}
& \mathrm{B}=\text { Lebar kapal }(\mathrm{m}) \\
& \mathrm{H}=\text { Dalam }
\end{aligned}
$$

Analisis kecepatan dilakukan dengan menggunakan rumus Hashimoto dalam Sumintadireja et al. (1982).

$$
\frac{B H P}{\Delta}=\frac{V}{\sqrt{ } L}
$$

Dimana : BHP = Brake hourse power

$$
\begin{aligned}
\Delta & =\text { Displacement tonnage } \\
\mathrm{V} & =\text { Kecepatan kapal (knot) } \\
\mathrm{L} & =\text { Panjang kapal (feet) }
\end{aligned}
$$

\section{HASIL DAN PEMBAHASAN}

\section{Deskripsi Kapal Purse Seine}

Kapal purse seine merupakan jenis alat tangkap encirceling atau kapal yang dioperasikan dengan cara melingkari gerombolan ikan. Kapal ini digunakan untuk membawa alat tangkap purse seine dengan target tangkapan ikan yang memiliki sifat schooling fish. Hal tersebut yang membuat kapal harus memiliki kapasitas dukung yang besar dan sebagai kapal yang membawa alat tangkap yang pengoperasiannya dengan cara dilingkarkan (Azis et al. 2017).

Pada umumnya kapal purse seine digunakan nelayan untuk menangkap ikan pelagis yang hidupnya bergerombolan dan ikan perenang cepat seperti ikan tuna, cakalang dan tongkol (Rizwan et al. 2017). Pengrajin kapal sering menyebut kapal purse seine dengan sebutan kapal gae pada lokasi penggalangan.

Kapal purse seine yang dijadikan sebagai bahan penelitian memiliki rancangan umum, rancangan umum pada (Gambar 1 ) digunakan untuk menggambarkan tata letak ruangan yang ada di atas kapal, di Indonesia pembuatan kapal ikan banyak dilakukan secara tradisional dimana pengrajin masih mengandandalkan keahlian secara turun temurun yang dipunya oleh orang terdahulunya, kemudian juga ada rencana garis (lines plan) (Gambar 2) Dalam rencana garis terbagi menjadi 3 yaitu body plan, profile plane dan breadth plan.
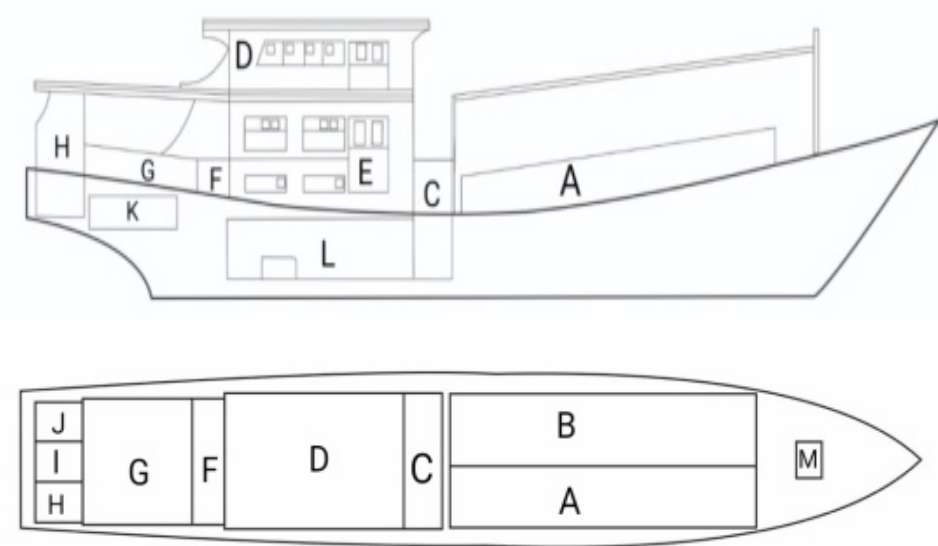

Gambar 1 Rancangan umum kapal purse sein 


$\begin{array}{lllll}\text { Seterangan : } & \text { A } & \text { : Ruang Palka } & \text { H } & \text { : Ruang Air Bersih } \\ \text { B } & \text { : Ruang Alat Tangkap } & \text { I } & \text { : Toilet } \\ \text { C } & \text { : Ruang BBM } & \text { J } & \text { : Ruang Air Bersih } \\ \text { D } & \text { : Ruang Kemudi } & \text { K } & \text { : Ruang Peralatan } \\ \text { E } & \text { : Ruang Akomodasi ABK } & \text { L } & \text { : Ruang Mesin } \\ \text { F } & \text { : Dapur } & \text { M } & \text { : Power block } \\ \text { G } & \text { : Ruang Makan } & & \end{array}$

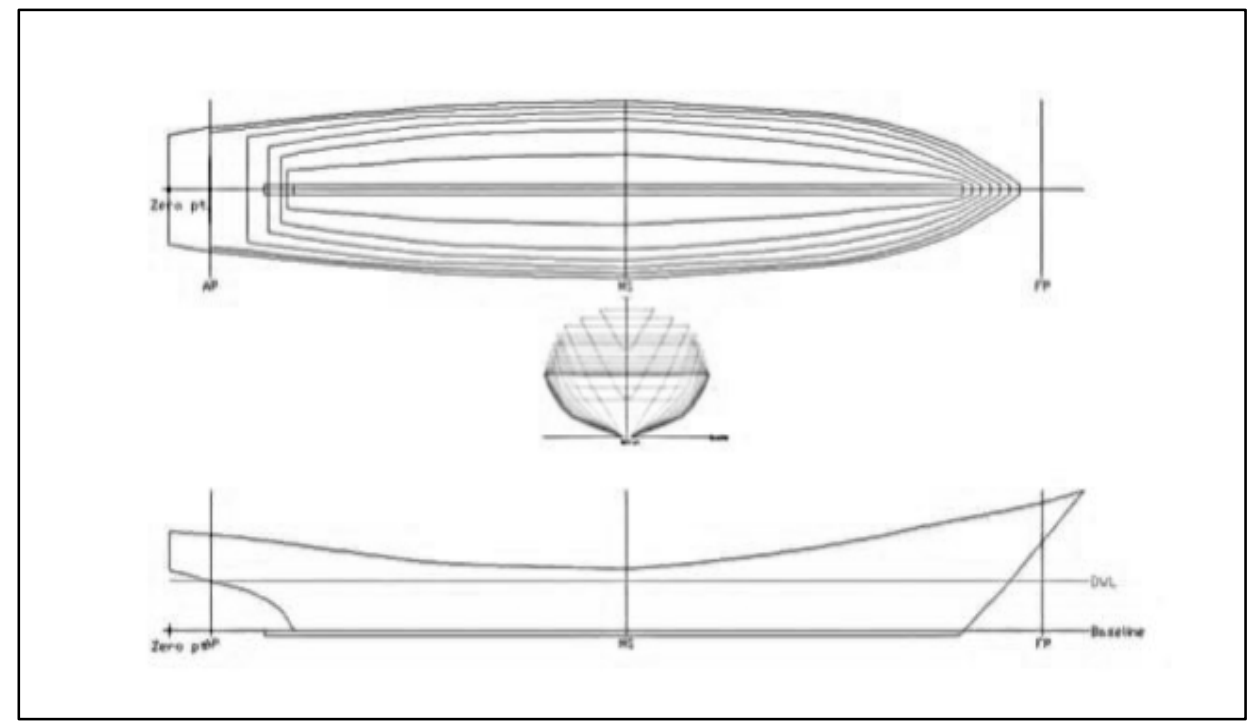

Gambar 2 Rencana garis (lines plan)

\section{Kontruksi dan Material Kapal Purse Seine}

Menurut Hablinur et al. (2014), konstruksi rangka perahu secara umum yaitu komponenkomponen suatu bangunan yang ada pada bagian perahu antara lain lunas bawah, lunas depan, wrang, lunas belakang, gading-gading dan komponen pendukung lainnya seperti Tabel 1.

Tabel 1 Kesesuaian bagian konstruksi kapal dengan BKI

\begin{tabular}{lcccc}
\hline \multirow{2}{*}{ Bagian Kontruksi Kapal } & \multicolumn{2}{c}{ Hasil Pengukuran } & \multicolumn{2}{c}{ Ketentuan BKI } \\
\cline { 2 - 5 } & Lebar $(\mathrm{mm})$ & Tinggi $(\mathrm{mm})$ & Lebar $(\mathrm{mm})$ & Tinggi $(\mathrm{mm})$ \\
\hline Lunas & 200 & 270 & 210 & 320 \\
Linggi & 200 & 240 & 180 & 265 \\
Haluan & 220 & 315 & 180 & 265 \\
Linggi & 70 & 110 & 65 & 101 \\
Buritan & 150 & 30 & 280 & 58 \\
Gading-gading & & & & \\
Galar & 130 & 70 & 120 & 70 \\
Balok & 220 & 46 & 260 & 46 \\
Balok & 200 & 200 & 220 & 230 \\
Geladak & 220 & 46 & 450 & 45 \\
Papan Geladak & & & & \\
Mesin & & &
\end{tabular}

Kontruksi yang digunakan dalam pembuatan kapal di galangan Desa Pagaruyung menggunakan material berbahan kayu, menurut Hasan dan Tatong (2005), kayu adalah suatu bahan bagian dari pohon setelah diperhitungkan bagian mana yang dapat dimanfaatkan dalam beberapa pemakaian, baik sebagai kayu pertukangan, kayu industri atau kayu bakar. material kayu 
yang digunakan dalam kontruksi pembuatan kapal purse seine ada 2 yaitu, kayu alaban atau laban dan kayu ulin, seperti pada Tabel 2.

Tabel 2. Material kapal purse seine dan kesesuaain BKI

\begin{tabular}{|c|c|c|c|c|c|}
\hline \multirow[t]{2}{*}{ No } & \multirow[t]{2}{*}{ Jenis Kayu } & \multirow{2}{*}{$\begin{array}{c}\text { Penggunaan di Atas } \\
\text { Kapal }\end{array}$} & \multicolumn{2}{|c|}{ Kelas } & \multirow{2}{*}{$\begin{array}{c}\text { Pemakaian Rekomendasi } \\
\text { BKI }\end{array}$} \\
\hline & & & Awet & Kuat & \\
\hline 1. & $\begin{array}{l}\text { Ulin } \\
\text { (Eusideroxylon } \\
\text { Zwageri } \\
\text { T.et.B.) }\end{array}$ & $\begin{array}{l}\text { Lunas, Linggi haluan, } \\
\text { linggi buritan, gading- } \\
\text { gading, galar balok, } \\
\text { balok geladak, papan } \\
\text { kulit, pondasi mesin. }\end{array}$ & 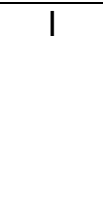 & I & $\begin{array}{l}\text { Semua bagian kapal, terutama } \\
\text { yang memerlukan kekuatan. }\end{array}$ \\
\hline 2. & $\begin{array}{l}\text { Laban (Vitex } \\
\text { pubesceus } \\
\text { vahl). }\end{array}$ & $\begin{array}{l}\text { Papan geladak, palka } \\
\text { ikan, bangunan, papan } \\
\text { kulit }\end{array}$ & I & I-II & $\begin{array}{l}\text { Kulit, Papan Geladak, gading, } \\
\text { lunas, galar, linggi, dll }\end{array}$ \\
\hline
\end{tabular}

1) Lunas

Data yang didapatkan dilapangan dari kapal purse seine pada bagian konstruksi lunas hanya memiliki lunas luar, Jika dilihat dari peraturan BKI hal tersebut telah sesuai karena kapal yang dijadikan objek lebih kecil dari 140 dengan menggunakan persamaan $L(B / 3+D)$. Ukuran pada lunas puse seine yang diteliti yaitu $200 \mathrm{~mm} \times 270 \mathrm{~mm}$, sedangkan aturan yang telah ditetapkan untuk lunas yaitu $210 \mathrm{~mm} \times 320 \mathrm{~mm}$, untuk panjang lunas pada kapal di lapangan memiliki 16,7 m. Material yang digunakan untuk bagian lunas yaitu kayu ulin (Eusideroxylon zwageri) Berdasarkan ketetapan BKI tentang kelas awet dan kelas kuat untuk kayu ulin maka di golongkan pada tingkat I dan untuk penempatan kayu ulin pada konstruksi kapal sudah tepat.

\section{2) Linggi Haluan dan Buritan}

Sesuai data hasil yang didapatkan untuk linggi haluan yaitu $200 \mathrm{~mm} \times 240 \mathrm{~mm}$ dengan panjang linggi haluan mencapai $350 \mathrm{~cm}$, sedangkan untuk nilai yang di tetapkan oleh BKI untuk linggi haluan dengan persamaan $L(B / 3+D)$ yaitu $170 \mathrm{~mm} \times 245 \mathrm{~mm}$ dan untuk linggi buritan data yang didapatkan yaitu $220 \mathrm{~mm} \times 315 \mathrm{~cm}$ sedangkan untuk perhitungan yang telah ditetapkan untuk linggi buritan ketetapan yang di tetapkan oleh BKI nilai linggi buritan memiliki tinggi sekurang kurangnya $5 \%$ berukuran besar dari linggi haluan dan lebar pada linggi buritan itu di perbolehkan sama. Untuk material yang digunakan pada linggi haluan dan linggi buritan juga menggunakan kayu ulin (Eusideroxylon zwageri) dan telah sesuai dengan ketetapan oleh BKI yang mengatakan bahan atau material kayu ulin cocok untuk digunakan untuk konstruksi bagian linggi pada kapal.

3) Gading - gading

Data yang diperoleh untuk gading-gading yang ada di galangan memiliki 2 gading yaitu gading kanan dan gading kiri dimana untuk ukuran kedua gading tersebut adalah sama yaitu 70 $\mathrm{mm} \times 11 \mathrm{~mm}$. Sedangkan untuk ukuran yang ditetapkan oleh pihak BKI dengan persamaan $\mathrm{L}(\mathrm{B} / 3$ $+D)$ serta $(B / 3+D)$ didapatkan nilai $65 \mathrm{~mm} \times 101 \mathrm{~mm}$. ukuran tersebut belum sesuai dengan ketetapan BKI perbedaan juga dterlihat dari perhitungan jarak gading data lapangan didapat 300 $\mathrm{mm}$ sedangkan perhitungan yang didapatkan dari ketetapan BKI untuk jarak gading bernilai 310 $\mathrm{mm}$ bebrebda $10 \mathrm{~mm}$. Pembuatan gading-gading kapal di Desa Pagaruyung terbuat dari bahan Ulin (eusideroxylon zwageri) bahan ulin di gunakan karena, ulin di kenal memiliki ketahanan yang kuat dari segi kelas awet dan kelas kuat, ulin tergolong ke dalam tingkat I dengan berat jenis $\geq 0,90$ dengan kukuh lentur $\geq 1100$ dan kukuh kekuatan itu $\geq 650$.

Menurut Anisa (2009) pemilihan material kapal merupakan tahapan penting yang harus diperhatikan dalam pembangunan kapal, karena dapat menentukan terkait usia pada sebuah kapal dalam menjalankan fungsinya.

4) Galar

Menurut Mullah (2010) galar pada kapal terbagi menjdai 2 yaitu galar balok dang alar kim, galar balok merupakan penyambung antara gading dari bagian depan sampai bagian belakang di tiap sisi kapal bagian atas, galar balok tepat terletak di bawah balok geladak sedangkan galar kim merupakan penyambung antar gading di tiap sisi kapal namun berada pada bagian bawah setelah 
galar balok tepatnya menempel pada bagian gading-gading yang melengkung. Pengukuran saat dilakukan dilapangan didapatkan nilai untuk galar balok dan galar kim sama yaitu $150 \mathrm{~mm} \times 30 \mathrm{~mm}$ kemudian pada persamaan $L(B / 3+D)$ oleh $B K I$ (1996) angka yang ditetapkan untuk keseuaian berbeda yaitu $280 \mathrm{~mm} \times 58 \mathrm{~mm}$, dari perbandingan tersebut didapatkan untuk nilai galar tidak sesuai.

Dalam segi material atau bahan yang digunakan untuk konstruksi kayu pada galar itu digunakan kayu berbahan ulin dimana untuk ukuran panjang galar itu sepanjang $8 \mathrm{~m}$ dengan panjang kapal mencapai $22 \mathrm{~m}$ maka pada bagian galar akan di lakukan penyambungan dimana perekatan pada gading menggunakan pasak kayu agar bagian sambungan tidak mengalami pecah.

\section{5) Balok Geladak dan Papan Geladak}

Perhitungan pada balok geladak yaitu $130 \mathrm{~mm} \times 70 \mathrm{~mm}$ namun namun dari kesesuaian yang di tetapkan oleh $B K I$ menggunakan $\mathrm{L}(\mathrm{B} / 3+\mathrm{H})$ dimana panjang balok geladak sesuai dengan hasil dilapangan yaitu $3,26 \mathrm{~m}$ dan kemudian didapatkan ukuran modulus penampang yaitu $5,4 \mathrm{~cm}^{3}$ dengan hasil W $98 \mathrm{~cm}^{3}$. kemudian dilakukan perhitungan dengan ketetapan BKI yaitu $120 \mathrm{~mm} \mathrm{x}$ $70 \mathrm{~mm}$ dari perbandingan tersebut nilai balok geladak tidak sesuai.

Sedangkan untuk papan geladak hasil yang didapatkan dilapangan yaitu $220 \mathrm{~mm} \times 46 \mathrm{~mm}$, sedangkan untuk ketetapan dari BKI adalah $260 \mathrm{~mm}$ x $46 \mathrm{~mm}$ dari kedua hal tersebut pada lebar papan mengalami perbedaan dan untuk tinggi atau ketebalan sama, dan untuk material yang digunakan pada balok geladak menggunakan kayu ulin dan untuk papan geladak bisa menggunakan kayu ulin dan juga bisa menggunakan kayu alaban dimana kelas awet kayu tersebut berada di kelas I sedangkan untuk kelas kuat kayu alaban itu I-II dimana berat jenis kayu tersebut $0,90-0,60$.

\section{6) Papan Kulit Kapal}

Data yang didapatkan pada saat dilakukan pengukuran papan kulit yaitu $220 \mathrm{~mm} \times 46 \mathrm{~mm}$, dari angka yang tertera untuk papan geladak dengan papan kulit memiliki ukuran yang sama setlah data didapatkan kemudian dilakukan perhitungan dengan persamaan $L(B / 3+D)$ di dapatkan hasil sesuai dengan ketetapan BKI adalah $450 \mathrm{~mm} \times 45 \mathrm{~mm}$, dari perbandingan antra nilai ketetapan BKI dengan nilai yang didapatkan dilapangan tidak sesuai. Dalam konstruksi bagian papan kulit material yang digunakan untuk pembuatan kapal sebagai objek peneliti pada papan kulit berbahan kayu ulin namun sebagian kapal yang ada di galangan Desa Pagaruyung juga ada yang menggunakan kayu berbahan alaban, untuk mereka yang memiliki berkelebihan rezeki maka pembuatan kapal untuk bagian papan kulit atau kulit luar lebih banyak menggunakan material berbahan ulin karena sudah di jamin akan usia kapal serta material berbahan kuat.

Kapal purse seine yang diteliti di galangan didapatkan bahwa pemasangan papan kulit mendahului dari pemasangan gading-gading, dimana para pengrajin mengatakan untuk daerah pagaruyung hal tersebut sudah menjadi kebiasaan dalam pembangunan kapal, dimana hal ini sesuai Menurut Umam (2007), bahwa pemasangan gading-gading yang mendahului kulit luar atau papan kulit akan membuat konstruksi kapal tersebut kurang terjadi gesekan yang mengakibatkan melemahnya konstruksi kapal.

\section{7) Pondasi Mesin Kapal}

Ukuran poondasi mesin pada kapal purse seinei adalah $200 \mathrm{~mm} \times 200 \mathrm{~mm}$ memiliki lebar dan tinggi yang sama, sedangkan untuk pondasi mesin yang ditetapkan oleh BKI dengan persamaan $\mathrm{L}(\mathrm{B} / 3+\mathrm{H})$ dimana nilai semula itu 59,4 maka hasil yang di dapat dari ketetapan ukuran yang semestinya untuk pondasi mesin itu $220 \mathrm{~mm} \times 230 \mathrm{~mm}$ dari hasil perbandingan ukuran pondasi mesin mmeiliki hasil yang tidak sesuai dengan ketetapan BKI. Kapal yang dibuat di galangan Desa Pagaruyung menggunakan material kayu yang berbahan kayu ulin dimana hal tersebut telah seuai dengan ketetapan yang ada peraturan BKI (1996) dimana pemakaian kayu ulin itu meliputi semua bagian kapal dan terutama yang memerlukan kekuatan, dalam hal tersebut pondasi mesin memerlukan pondasi yang kuat agar peletakan mesin kapal tidak goyah atau rusak akibat getaran atau gesekan saat mesin bekerja kayu ulin cocok untuk digunakan untuk konstruksi tersebut. 


\section{Tonnage Kapal purse seine}

Tonnage atau tonase pada kapal purse seine membahas mengenai perhitungan mengenai volume pada kapal. Gross tonnage atau GT adalah suatu ukuran yang digunakan untuk menunjukkan besarnya volume pada kapal (Sunardi et al. 2019). Saat dilakukan pengukuran di dapatkan ukuran dimensi utama pada kapal sesuai dengan Tabel 3.

Tabel 3 Ukuran dimensi utama

\begin{tabular}{lc}
\hline \multicolumn{1}{c}{ Keterangan } & Jenis dan Ukuran \\
\hline Panjang Seluruhnya (LOA) & 22,00 meter \\
Panjang Antara Garis Tegak (LPP) & 19,03 meter \\
Panjang Garis Muatan Penuh (LWL) & 20,00 meter \\
Lebar (B) & 3,90 meter \\
Tinggi (D) & 1,40 meter \\
Sarat Air (d) & 1,12 meter \\
Cb & 0,472 \\
\hline
\end{tabular}

Dari hasil Tabel 3pada bagian dimensi utama kapal berjenis tipe purse seine memiliki panjang keseluruhan (LOA) mencapai 22 meter, sedangkan untuk panjang antara garis tegak (LPP) memiliki panjang 19,03 meter, kemudian didapatkan nilai panjang garis muatan penuh (LWL) adalah 20,00 meter, LWL ditujungkan untuk mengetahui garis air pada kapal saat berada di permukaan perairan dan untuk lebar pada kapal mencapai 3,90 meter, lebar ditunjukan untuk mengetahui besar ruangan pada kapal kemudian pada ketinggian kapal mencapai 1,40 dan untuk sarat air pada kapal bernilai 1,12 meter, sedangkan untuk $\mathrm{Cb}$ (Coefficient block) bernilai 0,472 cb ditunjukan untuk perbandingan dari isi crane dengan isi suatu bak dengan panjang kapal (L), lebar kapal (B) dan tinggi pada kapal yang dimana nilai cb dapat mendeskripsian tingkat kegemukan kapal.

Pada panjang utama kapal atau LOA didapatkan memiliki panjang 22 meter yang dimana ukuran tersebut kurang dari 24 meter, jika panjang utama kapal kurang dari 24 meter maka perhitungan dilakukan dengan cara pengukuran internasional sesuai dengan Dirjen PERLA No. PY.67/1/16-02, kemudian untuk GT kapal purse seine yang di jadikan sebagai objek penelitian di Galangan Desa Pagaruyung di dapatkan berukuran 24,92 GT. Adapula perhitungan untuk penampang pada kapal menurut Anung (1993) Penampang konstruksi atau scantling adalalah ukuran penampang yaitu (tebal $\mathrm{x}$ lebar, $\mathrm{t} \times \mathrm{I}$ ), untuk mendapatkan ukuran dari penampang di gunakan rumus yang telah ditetapkan oleh BKI (1996) yaitu $L(B / 3+D)$ hasil yang didapat dengan menggunakan rumus ketetapan oleh BKI diketahui penampang konstruksi pada kapal purse seine yang dijadikan sebagai objek penelitian adalah 59,4 $\mathrm{m}^{2}$ sedangkan untuk rumus Perkiraan Percepatan Teoritis pada kapal purse seine dengan menggunakan rumus hashimoto didapatkan untuk kecepatan pada kapal purse seine yang ada di galangan itu 13,35 knot.

\section{SIMPULAN}

Material untuk pembuatan kapal purse seine menggunakan kayu ulin (Eusideroxylon zwageri) pada bagian lunas, linggi haluan dan linggi buritan, gading-gading, galar balok, balok geladak, papan kulit dan pondasi mesin, kayu alaban atau laban (Vitex pubesceus) digunakan pada bagian papan geladak, palka ikan, bangunan dan papan kulit pemakaian kayu pada material sesuai dengan BKI dan Konstruksi kapal tidak sesuai dengan aturan yang ditetapkan BKI.

\section{DAFTAR PUSTAKA}

Anisa FR. (2009). Tingkat keakuratan konstruksi gading-gading kapal kayu galangan kapal Ud. Semangat Untung di Desa Tanah Beru, Bulukumba, Sulawesi Selatan. Skripsi. Institut Pertanian Bogor. 
Azis MA, Iskandar BH, Novita Y. (2017). Kajian Desain Kapal Purse Seine Tradisional di Kabupaten Pinrang (Studi Kasus KM. Cahaya Arafah). Albacore, 1(1): 69-76.

[BKI] Biro Klasifikasi Indonesia. (1996). Buku Peraturan Klasifikasi dan Konstruksi Kapal Laut. Peraturan Kapal Kayu. Jakarta (ID): BKI.

Direktorat Jendral Perhubungan Laut. (2002). Keputusan Direktur Jendral Perhubungan Laut No. PY.67/1/16-02 Tentang Perubahan atas Keputusan Direktur Jendral Perhubungan Laut No. PY.67/1/13-90. Jakarta: Kementrian Perhubungan.

Febriyansyah B, Imron M, Iskandar BH. (2009). Kesesuaian Ukuran Beberapa Bagian Konstruksi Kapal Ikan di PPI Muara Angke Jakarta Utara dengan Aturan Biro Klasifikasi Indonesia. Buletin PSP, 18(3): 177-184.

Hablinur, Duskiardi, Burmawi. (2014). Proses Pembuatan Rangka Kayu Sebagai Tulang pada Perahu Nelayan Berbahan Komposit. Jurnal Fakultas Teknologi Industri, 10(4): 1-10.

Hasan H, Tatong B. (2005). Pengaruh Pemadatan terhadap Sifat Fisis dan Mekanis Kayu Palapi. Media Komunikasi Teknik Sipil, 13(1): 1-15.

Iskandar BH, Novita Y. (2000). Tingkat Teknologi Pembangunan Kapal Ikan Kayu Tradisional di Indonesia. Jurnal Buletin PSP, 9(20): 53-67.

Mullah A. (2010). Kesesuaian ukuran beberapa bagian konstruksi kapal kapal penangkap ikan di PPN Palabuhanratu Jawa Barat dengan aturan Biro Klasifikasi Indonesia. Skripsi. Fakultas Perikanan dan IImu Kelautan. Institut Pertanian Bogor.

Rizwan, Setiawan I, Rahmini SAE, Dewiyanti I, Purnama NR, Arif M. (2017). Desain dan Studi Konstruksi Kapal Purse Seine Bermaterial Kayu di Pelabuhan Perikanan Samudera (PPS) Lampulo. Prosiding Seminar Nasional II USM 2017, 1: 91-99.

Rusmilyansari, Iriansyah dan Aminah S. (2014). Pembangunan Kapal Perikanan Di Galangan Kapal Tradisional Kalimantan Selatan. Fish Scientiae, 4(8): 95 - 109.

Suharsimi. (2002). Metodologi Penelitian. Jakarta (ID): PT. Rineka Cipta.

Sumintadireja AS, Edi, Chairul N. (1982). Pengkajian Motoritas Perikanan di Kabupaten Pacitan. Laporan Penelitian Perikanan Laut No. 24: 77-124. Jakarta (ID): Balitkanlut.

Sunardi, Baidowi A, Yulianto ES. (2019). Perhitungan GT Kapal Ikan Berdasarkan Peraturan di Indonesia dan Pemodelan Kapal dengan Dibantu Komputer (Studi Kasus Kapal Ikan Muncar dan Prigi). Marine Fisheries, 10(2): 141-152.

Umam M. (2007). Desain dan konstruksi kapal purse seine "Semangat Baru" di Galangan Kapal Pulau Tidung. Skripsi. Fakultas Perikanan dan IImu Kelautan, Institut Pertanian Bogor. 